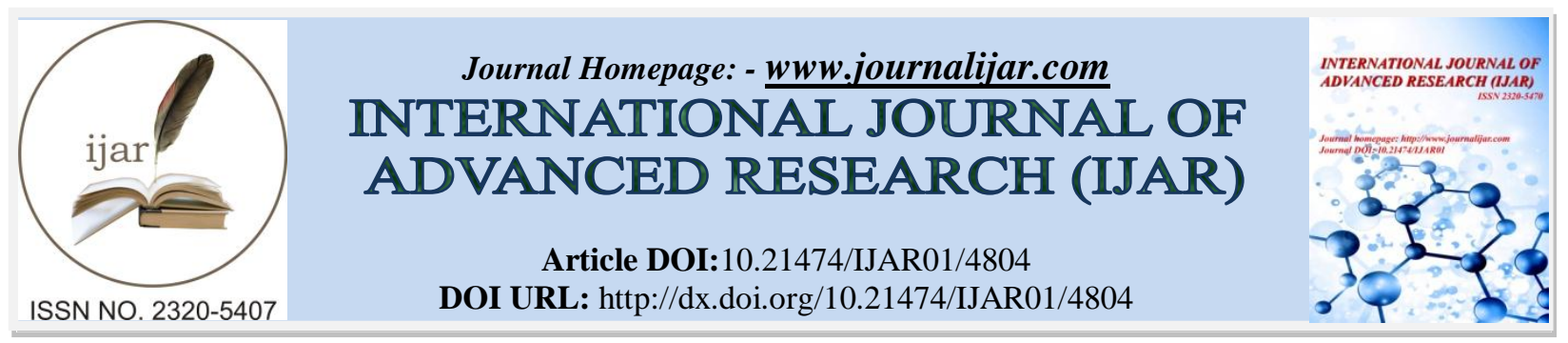

RESEARCH ARTICLE

\title{
LEFT ATRIUM FUNCTION ASSESSMENT IN HYPERTENSIVE PATIENTS.
}

M. Ztati, L. Bendriss and A. Elkhatouri.

Service de cardiologie, hôpitalmilitaireAvicenne.CHU Mohammed VI Marrakech.

\section{Manuscript Info}

Manuscript History

Received: 10 May 2017

Final Accepted: 12 June 2017

Published: July 2017

Key words:-

Arterial high blood pressure -LA

function - mild diastolic dysfunction

\section{Abstract}

Introduction It has been established that the volume of left atrium (LA) is a marker of alteration of the diastolic function of the left ventricle. The aim of this study is to determine the relationship between left atrium remodeling and left ventricle diastolic dysfunction in hypertensive patients with preserved systolic function and The repercussions of high blood pressure (HTA) on size and function LA

Materials and methods: A prospective study of 200 hypertensive patients In the cardiology department of the Avicenne military hospital in Marrakech during the period from July 2015 to July 2016,

Résultats: The average age of hypertensive patients was $52 \pm 5$ years, 80 men, whose data were all evaluated by echocardiography measuring left atrium volumes during the reservoir, conduit and pump phases. Standard indices reflecting left ventricular filling were also assessed.

Medium left atrium volume indexed for body surface was significantly higher in hypertensive patients $32.1 \pm 4.6 \mathrm{ml} / \mathrm{m} 2$ vs $21.72(2.52) \mathrm{mL} / \mathrm{m}^{2}$. When compared to normal subjects, patients with mild diastolic dysfunction had lower corrected passive emptying volumes $(\mathrm{p}<0.001)$ and higher corrected active emptying volumes, thus leading to similar corrected total emptying volumes $(\mathrm{p}<0.001)$. However, patients with moderate diastolic dysfunction had smaller active emptying volumes, but higher passive and total emptying volumes when compared to normal controls and patients with mild diastolic dysfunction.

Conclusion: The HTA induces an increase in the pump function and the reservoir function and an alteration of the function of the LA; These changes appear to be related to left ventricular hypertrophy and the degree of left ventricular diastolic dysfunction.

Copy Right, IJAR, 2017,. All rights reserved.

\section{Introduction:-}

The left atrium (OG) plays an important role in the proper functioning of the heart thanks to its three functions: reservoir, duct and pump. Several pathologies directly or indirectly lead to morphological and functional modifications of the GA. Impairment of left atrium function often occurs in patients with moderate to severe hypertension. It has been established that the volume of $\mathrm{OG}$ is a marker of alteration of the diastolic function of the left ventricle. This alteration is a risk factor for the occurrence of atrial fibrillation according to the Framingham study which revealed that a $5 \mathrm{~mm}$ increase in the size of the OL produced a $39 \%$ increase in the incidence of AF. 
The objective of our study is to analyze the effect of hypertension (hypertension) on size and function OG.

\section{Matérielse Method:-}

We undertook a prospective study in 200 patients in the cardiology department of the Avicenne Military Hospital in Marrakech during the period from July 2015 to July 2016. The exclusion criteria included a history or signs of a " Atrial arrhythmia, history of congenital heart disease, rheumatic heart disease, valvular surgery, coronary artery disease, or poor echocardiography Window. All subjects gave their informed written consent to the study.

Hypertension has been defined as the use of antihypertensive or persistent elevation of blood pressure above 140/90 $\mathrm{mm} \mathrm{Hg}$ on two or more occasions with the patient sitting for at least five minutes

\section{Résultats:-}

Out of 200 patients, the patients were divided into 120 women, $60 \%$ of the cases, 80 men or $40 \%$ of the cases. The sex ratio is 1.5 .

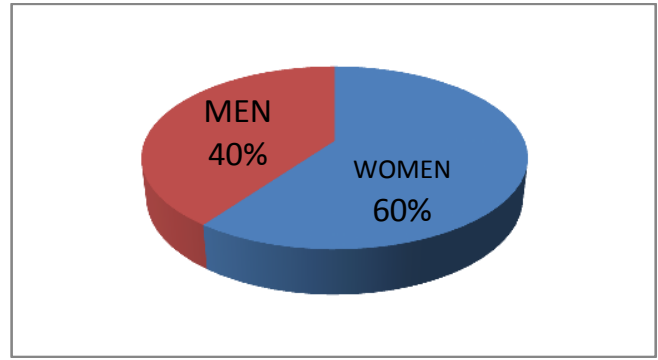

Figure 1:-Demographics of ourpatients.

The mean age of the patients was $52+/-5$ years with extremes of 30 to 83 years.

The associated cardiovascular risk factors (Table I) were smoking, dyslipidemia and android obesity. High blood pressure was controlled in $80 \%$ of cases. Obesity was present in 60 of our patients, $30 \%$ of cases.

Thirty of our patients had diabetes, ie $15 \%$ of cases and 20 patients had a history of stroke, $10 \%$ of cases.

Table I: -associated cardiovascular risk factors

\begin{tabular}{|c|c|c|}
\hline risk factor & Number & $\mathrm{P}(\%)$ \\
\hline Smoking & 94 & $35 \%$ \\
\hline Dyslipidémia & 48 & $24 \%$ \\
\hline Obesity & 60 & $30 \%$ \\
\hline Male > 55 years & 94 & $47 \%$ \\
\hline Women > 65 years & 32 & $16 \%$ \\
\hline Diabète & 30 & $15 \%$ \\
\hline
\end{tabular}

The most commonly used antihypertensive agents (FIG. 2) were ACE inhibitors in 96 patients, ie $48 \%$ of the cases diuretics in 66 patients or $33 \%$ of the cases, the ARA II in 70 patients or $35 \%$ of the cases, Calcium channel blockers in 54 patients (27\%) and beta-blockers were prescribed in 8 patients $(4 \%)$.

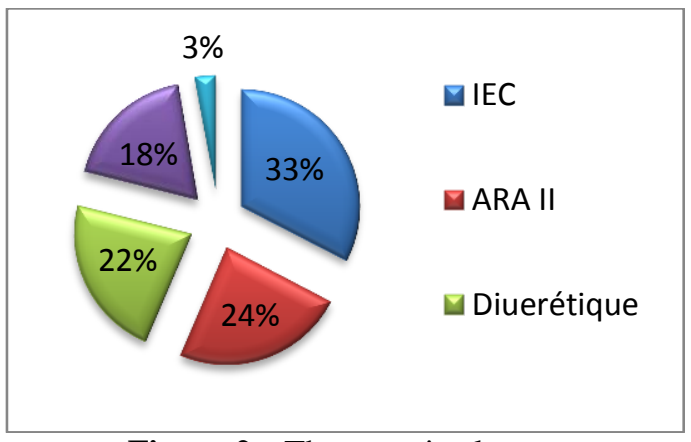

Figure 2:- Therapeutic classes. 
More than half of the patients $52 \%$ were undergoing dual therapy, $77 \%$ in combination and $23 \%$ in free association and $5 \%$ in triple therapy.

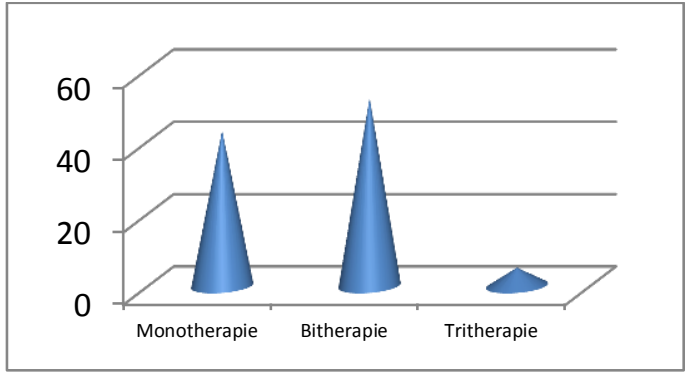

Figure 3:-TherapeuticProfile.

Prospective study involving 100 hypertensive patients to 100 patientsLA volumes were measured in transthoracic echocardiography at different times of the cardiac cycle: telesystole (maximal volume (max flight)) at the time of mitral closure (Minimum Volume Min (Vol Min)) and immediately before contraction LA (Volume LA pre A (Pre A flight)). The reservoir function indices (the total drain volume and the expansion index), the ducted function (passive drain volume and passive drain fraction) and the pump function (active emptying volume and active drain fraction) Have been calculated.

Hypertensive patients were classified into 2 groups: with the left hypertrophic ventricle $(\mathrm{LVH})(75 \% \mathrm{n}=150)$ and the group II without $\mathrm{LVH}(25 \% \mathrm{n}=50)$

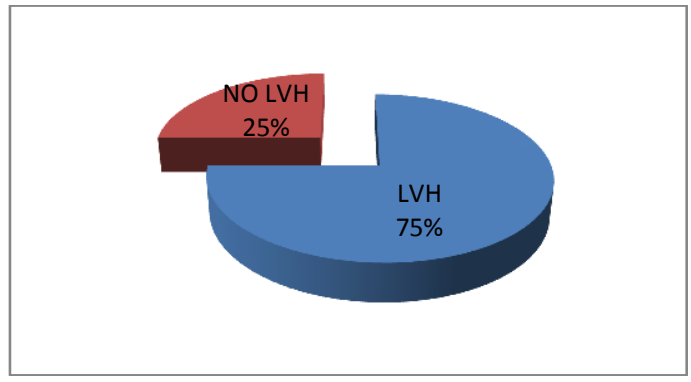

Figure 4:- Left ventricular hypertrophy in our patients.

- Maximum volume of LA:

An increase in the size of the LA Maximum volume in 155 of our patients $>28 \mathrm{ml} / \mathrm{m} 2$

\begin{tabular}{|c|c|c|c|}
\hline & HTAgroup & Witnesses group & $\mathrm{P}$ \\
\hline Volume max & $63,3+/-4$ & $48,3+/-4$ & $<0,001$ \\
\hline Volume max ind & $33.2+/-5$ & $24,4+/-6$ & 0,001 \\
\hline
\end{tabular}

- Minimum volume of the LA:

An increase in the minimum volume of OL in 115 of our patients is $57.5 \%$ (> $13 \mathrm{ml} / \mathrm{m} 2)$.

\begin{tabular}{|c|c|c|c|}
\hline & & & $\mathrm{P}$ \\
\hline Volume min & $18+/-5.6$ & $16+/-8.3$ & 0.01 \\
\hline Volume inde & $15,5+/-4.5$ & $13,3+/-4$ & 0.001 \\
\hline
\end{tabular}

PréA:

- Pre A volumeisincreased in 125 of ourpatients $>15 \mathrm{ml} / \mathrm{m} 2$

\begin{tabular}{|c|c|c|c|}
\hline & Patients & Witnesses & P \\
\hline Pré A & $46.4+/-5.3$ & $31.1+/-11.2$ & $<0.001$ \\
\hline
\end{tabular}




\section{$\checkmark \quad$ FE $p$ conduit function:-}

Thefunctionwasimpaired in 110 of ourpatients

\begin{tabular}{|l|l|l|l|}
\hline & Patients & Witnesses & P \\
\hline FE p & $24+/-5$ & $30+/-3$ & $<0,01$ \\
\hline
\end{tabular}

\section{$\checkmark$ FEapumpe function:-}

The LA pumpfunctionwasincreased in 101 of ourpatients

\begin{tabular}{|l|l|l|l|}
\hline & Patients & Witnesses & P \\
\hline FE a & $36+/-10$ & $26+/-8$ & $<0,001$ \\
\hline
\end{tabular}

\section{$\checkmark$ Réservoir function:-}

The LA reservoirfunctionwasincreased in 111 of ourpatients> $49 \%$

$111(49 \pm 5 \%): 64$ present 1 FDRCV

47 have at least 2 FDRCVs

\begin{tabular}{|l|l|l|l|}
\hline & Patients & Witnesses & P \\
\hline Reservoir Function & $47+/-4$ & $54+/-7$ & $<0.001$ \\
\hline
\end{tabular}

In thisstudy, the use of antihypertensivedrugshad no influenceonthesize of the LA. However, thegrouptakingcalciumchannelantagonistsappearstohavehad a largersize of the LA.

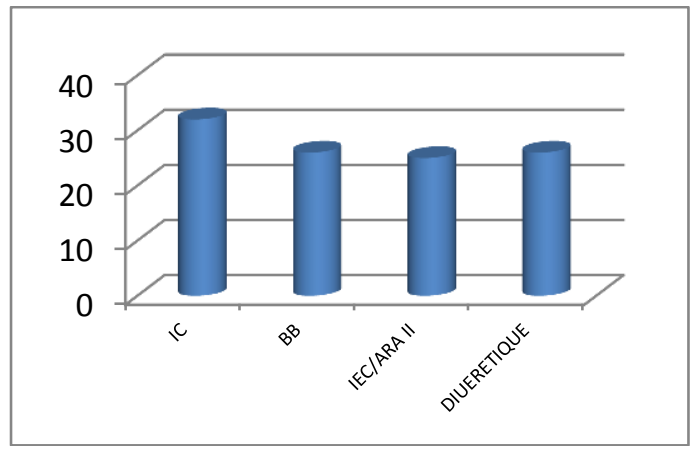

Figure 5:-Effect of antihypertensiveagentsonthevolume of LA.

\section{Discussion:-}

Theresults of ourstudy show thatthe HTA leads toanincrease in thesize of the OG (Maximumvolume, minimumvolume and pre-A volume.) Thereservoirfunction of the LA consideredonthe total dischargevolumewasgreater. $\quad$ Functionwasimpaired in ourhypertensivepatientswith a significantlylowerpassivedrainagefraction,

Thisdecreasewasgreater in thepresence of left ventricular hypertrophy. The LA pumpfunctionwasincreasedwith a larger active drainfraction. Thisincreasewasgreater in thepresence of diastolicdysfunction $(p=0.029)$. Ourresults are consistentwiththosereported in the ZAKHAM series (1).

The mean value of the OG passivedrainagefractionwasslightlyhigherthanthatobtained In otherstudies (2), whilethevalue of the active drainfraction of LA wasslightlylower,

Accordingto a studybyErol et al. Whohaveidentifiedthesamemodel in theirstudyOnHealthyAthletes (3).

In additiontothis, wehaveshownthat in patientswithmilddiastolicdysfunctionThevolume of active drainageincreasesThisis a compensatorymechanismthatreplacesthepassivedecreasefunctionperformed in orderto preserve the total volume of drainage Of the OG.

The role of LA size as a marker of LV diastolic function is well known (4,5). Accordingly, we found a strong correlation between LA volume index and LV diastolic function grade. Tsang et al. (6) have previously demonstrated that LA volume index was associated with increased severity of the LV diastolic dysfunction. During the diastole, the LA is directly exposed to LV pressure, which rises proportionally with the degree of LV diastolic 
dysfunction. Consequently, LA pressure elevates, surpassing the LV pressure and allows an appropriate LV filling. As a result of the elevated pressure, the LA wall tension rises, triggering the stretching and dilatation of the LA. This leads us to conclude that elevated LA volume is a response to chronic exposure to elevated LV pressure, which occurs in the presence of LV diastolic dysfunction. We also demonstrated that patients with moderate diastolic dysfunction had smaller active emptying volumes, but higher passive and total emptying volumes when compared to normal controls and patients with mild diastolic dysfunction. This phenomenon could be explained by the rise in LA pressure with increasing LV diastolic dysfunction. Otherwise said, the LA responds to elevated LV pressure by increased wall tension and dilatation, which, according to the Frank-Starling law, triggers a subsequent rise in atrial pressure. Elevated LA pressure overwhelms the already increased LV pressure and allows a "pseudonormal" LV fi lling, predominantly in the fi rst part of the diastole. Consequently, the LA systole, and, implicitly, the LA active emptying volume, will have a smaller contribution to LV filling

Moreover, we managed to prove that the LA volume index has a greater prognostic value for diastolic dysfunction development by comparison with the LA area index or the LA diameter index. This is not a surprising result, since diameter measurements have already been dismissed as insufficient by several authors (7,8). In addition to that, we calculated the LA volume index using volume measurements based on the Simpson's single plane modified rule, which seems to be preferred by most, as it considerably reduces errors derived from geometrical assumptions (10).

\section{Conclusion:-}

The HTA induces an increase in the pump function and the reservoir function and an alteration of the function of the OG; These changes appear to be related to left ventricular hypertrophy and the degree of left ventricular diastolic dysfunction

\section{References:-}

1. Retentissement de l'hypertensionartériellesur la fonction de l'oreillette gauche évaluée par échocardiographiebidimensionnelle.Zakhama L, Amri A, Antit S, Boussabah E, Herbegue B, Annabi MS, Nooman A, Marzougui Y, Thameur M, Ben Youssef S La tunisieMedicale - 2015 ; Vol $93\left(\mathrm{n}^{\circ} 06\right)$ : 403

2. Sirbu C, Herbots L, D'hooge J, Claus P, Marciniak A, Langeland T, Bijnens B, Rademakers FE, Sutherland GR: Feasibility of strain and strain rate imaging for the assessment of regional left atrial deformation: a study in normal subjects. Eur. J. Echocardiogr. 7, 199-208 (2006)

3. Erol MK, Ugur M, Yilmaz M, Acikel M, Sevimli S, Alp N: Left atrial mechanical functions in elite male athletes. Am. J. Cardiol. 88, 915-917 (2001)

4. Appleton CP, Kovacs SJ: The role of left atrial function in diastolic heart failure. Circ. Cardiovasc. Imaging 2, 6-9 (2009)

5. Blume GG, Mcleod CJ, Barnes ME, Seward JB, Pellikka PA, Bastiansen PM, Tsang TS: Left atrial function: physiology, assessment, and clinical implications. Eur. J. Echocardiogr. 12, 421-430 (2011)

6. Tsang TS, Barnes ME, Gersh BJ, Bailey KR, Seward JB: Risk for atrial fi brillation and congestive heart failure in patients $\geq 65$ years of age with abnormal left ventricular diastolic relaxation. Am. J. Cardiol. 93, 54-58 (2004)

7. Cui Q, Wang H, Zhang W, Wang H, Sun X, Zhang Y, Yang H: Enhanced left atrial reservoir, increased conduit, and weakened booster pump function in hypertensive patients with paroxysmal atrial fi brillation. Hypertens. Res. 31, 395-400 (2008)

8. Tops LF, van der Wall EE, Schalij MJ, Bax JJ: Multi-modality imaging to assess left atrial size, anatomy and function. Heart 93, 1461-1470 (2007)

9. Lang RM, Bierig M, Devereux RB, Flachskampf FA, Foster E, Pellikka PA, Picard MH, Roman MJ, Seward J, Solomon SD, Spencer KT, Sutton MS, Stewart WJ: Recommendations for chamber quantification: a report from the American Society of Echocardiography's Guidelines and Standards Committee and the Chamber Quantification writing group, developed in conjunction with European Association of Echo-cardiography, a branch of the European Society of Cardiology. J. Am. Soc. Echocardiogr. 18, 1440-1463 (2005)

10. Khoo CW, Krishnamoorthy S, Lim HS, Lip GY: Assessment of left atrial volume: a focus on echocardiographic methods and clinical implications. Clin. Res. Cardiol. 100, 97-105 (2011)

11. 16. Kurt M, Wang J, Torre-Amione G, Nagueh SF: Left atrial function in diastolic heart failure. Circ. Cardiovasc. Imaging 2, 10-15 (2009). 